\title{
USO DE MICROORGANISMOS PARA A BIORREMEDIAÇÃO DE AMBIENTES IMPACTADOS
}

\author{
Aline Ramalho Brandão Pereira'; Diego Antônio França de Freitas ${ }^{1}$ \\ 1- Universidade Federal de Lavras (UFLA - MG)
}

\section{RESUMO}

Nas últimas décadas, os problemas ambientais têm se tornado cada vez mais críticos e frequentes, principalmente devido ao desmedido crescimento populacional e ao aumento da atividade industrial. A observação de como o meio ambiente reage a cada intervenção antropogênica mostra a atuação de micro-organismos na busca da autopreservação, degradando os poluentes e utilizando-os como fonte de nutrientes. O uso de micro-organismos como ferramentas para a remediação de ambientes contaminados é chamada de biorremediação. Neste presente artigo, pretendeu-se reunir trabalhos que justifiquem a utilização de micro-organismos como uma alternativa biológica viável para a remediação de ambientes contaminados, visando a utilização deste paper como ferramenta didática para a educação ambiental em ambientes universitários.

Palavras-chave: Biodegradação. Micro-organismos. Poluentes. Educação Ambiental

\section{ABSTRACT}

In the last decade the environment problems have being more critical and frequent, mainly due to the population growth and the increase of industrial activities. The observation of microbial answer to the human environmental intervention, shows the capacity of these organisms in degrading the pollutant and its utilization as source of nutrients. Therefore, the use of microorganisms in degrading the pollutant presents in polluted areas is called bioremediation. The main of these project is join some papers that justify the use of microorganisms in the remediation of polluted areas, as a didactic tool in the environmental education at universities.

Keywords: Biodegradation. Fungi. Bacterials.Yeasts. Polluents.

\section{INTRODUÇÃO}

Nas últimas décadas, os problemas ambientais têm se tornado cada vez mais críticos e frequentes, principalmente devido ao desmedido crescimento populacional e ao aumento da atividade industrial. Com estes ingredientes, os problemas devido à ação antrópica têm atingido dimensões catastróficas, podendo ser observados por meio de alterações na qualidade do solo, do ar e da água (FREIRE et al., 2000).

As atividades industriais atraíram novos problemas devido à eliminação de rejeitos tóxicos provenientes de subprodutos gerados pelas indústrias. A eliminação desses produtos é, atualmente, um dos mais importantes assuntos em controle de poluição, o que tem levado os pesquisadores a buscarem novas técnicas e ferramentas mais poderosas que visem à remoção desses compostos do ambiente (ANDRADE, 2003).

A observação de como o meio ambiente reage a cada intervenção antropogênica mostra a atuação de micro-organismos na busca da autopreservação, degradando diversos poluentes e 


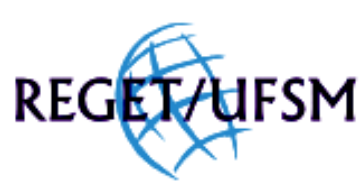

Pereira \& Freitas, v(6), no 6, p. $975-1006,2012$.

utilizando-os como fonte de nutrientes. Assim, estes micro-organismos constituem uma poderosa arma de defesa ambiental, passível de ser potencializada (BRITO et al., 2004).

O uso de micro-organismos como ferramentas para a remediação de ambientes contaminados é chamado de biorremediação. Este processo pode ser realizado por meio de um ou mais consórcios microbianos, indígenas ou não, para a degradação de contaminantes orgânicos poluentes (PEREIRA; LEMOS, 2003).

Assim, neste projeto pretendeu-se reunir trabalhos que justifiquem a utilização de microorganismos como uma alternativa biológica viável no tratamento de resíduos e para a remediação de ambientes contaminados, visando à sua utilização como ferramenta didática na educação ambiental em ambientes universitários.

\section{REFERENCIAL TEÓRICO}

\section{Crescimento populacional e contaminação de água, ar e solo}

O crescimento exacerbado da população acarretou o estabelecimento de conglomerados de alta densidade populacional, o que contribui significativamente para o fenômeno de contaminação ambiental, em função do aumento da quantidade de resíduos produzidos. Por sua vez, a atividade industrial que cresce assustadoramente satisfazendo o consumismo que caracteriza nossa sociedade, contribui com grandes volumes de resíduo de natureza diversa, os quais, geralmente, carregam espécies químicas de caráter tóxico (BRITO et al., 2004).

Ao longo de décadas, a atividade industrial tem produzido rejeitos gasosos, líquidos e sólidos nocivos ao ambiente. Substâncias químicas xenobióticas (produzidas pelo homem) têm alterado consideravelmente a qualidade dos ecossistemas. Da mesma forma, processos industriais que utilizam grandes volumes de água contribuem significativamente com a contaminação dos corpos d’água, principalmente pela ausência de sistemas de tratamento para os grandes volumes de efluentes líquidos produzidos (FREIRE et al., 2000).

A contaminação de águas naturais tem sido um dos grandes problemas da sociedade moderna. A economia de água em processos produtivos vem ganhando especial atenção devido ao valor agregado que tem sido atribuído a este bem, por meio de princípios, como consumidor pagador e poluidor pagador, recentemente incorporados a nossa legislação (KUNZ; ZAMORA, 2002).

O lançamento de matéria orgânica em corpos d'água produz uma série de efeitos, como o consumo de $\mathrm{O}_{2}$ e eutrofização dos mananciais, além de gosto e odor nas fontes de abastecimento de água. Os metais pesados que se encontram adsorvidos a esta matéria orgânica, podem se bioacumular ao longo da cadeia trófica e atingir a saúde humana. A alteração da cor e turbidez e a presença de óleos e materiais flutuantes provocam uma série de inconvenientes para a estação de tratamento de água (ETA) e alteração da estética do manancial. Os materiais sedimentáveis podem provocar o assoreamento de rios e represas e a queda de velocidade dos cursos d'água (Secretaria do Meio Ambiente do Estado de São Paulo).

Os poluentes podem alcançar as águas superficiais e subterrâneas de forma pontual ou difusa. As fontes pontuais compreendem a descarga de efluentes a partir de indústrias e estações de tratamento de esgoto, dentre outras. Estas fontes são de identificação bastante fácil e, portanto, podem ser facilmente monitoradas. Já as fontes difusas se espalham por inúmeros locais e são difíceis de serem determinadas em função das características intermitentes de suas descargas e também da abrangência sobre extensas áreas. Fontes difusas incluem o escoamento 


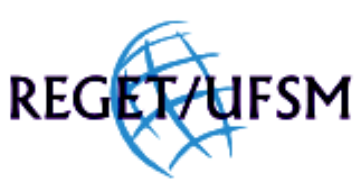

Pereira \& Freitas, v(6), no 6, p. $975-1006,2012$.

superficial urbano, o escoamento superficial de áreas agrícolas e a deposição atmosférica (BUNCE, 1994).

Muitas destas substâncias ainda não têm um método adequado de tratamento estabelecido e, assim, efluentes não eficientemente tratados, contendo ainda alta carga poluidora, têm sido descartados no meio ambiente o que pode ocasionar uma série de distúrbios ambientais (DELLAMATRICE, 2005).

Nos últimos anos, a legislação brasileira tornou-se restritiva quanto ao tratamento de efluentes lançados em corpos aquáticos. Segundo a Resolução no 357 do Conselho Nacional do Meio Ambiente (CONAMA), os efluentes de qualquer fonte poluidora somente poderão ser lançados, direta ou indiretamente, nos corpos de água, após o devido tratamento e desde que obedeçam às condições, aos padrões e às exigências propostos.

A poluição do solo também tem despertado o interesse dos especialistas, das autoridades e da sociedade. A preservação do mesmo é importante não só sob o aspecto ambiental, mas também de saúde pública. Por tradição, o solo tem sido utilizado como receptor de substâncias resultantes das atividades humanas, principalmente para a disposição final de resíduos, o que pode agravar os problemas do solo, como a erosão e o esgotamento dos minerais (GUNTHER, 2005).

A introdução de contaminantes no solo pode resultar na perda de algumas ou várias funções do mesmo e provocar a contaminação das águas subterrâneas. A presença de contaminantes no solo, originados de várias fontes, acima de certos níveis, provoca uma série de consequências negativas para a cadeia alimentar, podendo atingir os diversos ecossistemas e o homem (RODRIGUES; DUARTE, 2003).

Quanto à poluição do ar, sabe-se que o avanço da tecnologia vem acompanhado de gastos de energia, fato que impulsiona um série de pesquisas relacionadas a fontes renováveis deste recurso. Produzir energia geralmente é o principal motivo da poluição do ar, pois automóveis, fábricas e usinas termoelétricas espalhadas pelo mundo utilizam, na maioria das vezes, a energia dos combustíveis fósseis. Os principais poluentes atmosféricos são os gases tóxicos lançados pelas indústrias e pelos veículos movidos a derivados do petróleo e os compostos tóxicos formados no ar a partir da reação desses gases na atmosfera (DEL PINO; KRÜGER; SCHROEDER, 1995).

O estabelecimento de leis internacionais que regulam a questão do gerenciamento ambiental, aliado à pressão por parte de governos e opinião pública, fez com que grandes esforços tenham sido dedicados ao desenvolvimento de tecnologias mais limpas para o tratamento de resíduos e a remediação de ambientes contaminados (BRITO et al., 2004).

Embora existam diversas tecnologias que utilizam processos físicos e/ou químicos para a descontaminação de ambientes poluídos, o processo biológico de biorremediação é uma alternativa ecologicamente mais adequada e eficaz para o tratamento de ambientes contaminados com moléculas orgânicas de difícil degradação e metais tóxicos (GAYLARD; BELLINASO; MANFIO, 2005).

\section{Tratamento de resíduos, biorremediação e educação ambiental}

Segundo Jacobi (2003), o enfoque da educação ambiental deve buscar uma perspectiva de ação holística que relaciona o homem, a natureza e o universo. Assim, questões relacionadas à problemática ambiental decorrente da disposição inadequada de resíduos agroindustriais e o conhecimento das mais diversas técnicas de remediação de áreas contaminadas, certamente 
estão inseridas dentro do contexto da educação ambiental.

Dentre as diversas vertentes abordadas dentro do contexto da educação ambiental que devem ser mais intensamente exploradas, destaca-se a biorremediação, pois, se os resíduos decorrentes das atividades humanas não receberem o devido tratamento, os problemas ambientais se agravarão progressivamente, podendo causar danos irreparáveis aos ecossistemas e consequentemente, ao homem.

Aliado a este problema, vale ressaltar a tendência atual de uma reflexão cada vez menos linear acerca dos parâmetros que devem ser abordados em educação ambiental, que tendem a ser cada vez mais abrangentes, visando o esclarecimento da população como um todo, sobre os diversos métodos de recuperação de áreas degradadas, bem como de tratamentos alternativos de resíduos.

É inquestionável a necessidade de se investir em métodos alternativos de tratamento de resíduos, bem como de remediação de áreas contaminadas, não apenas com o desenvolvimento da tecnologia em si, mas, fundamentalmente, mediante o despertar da consciência humana e coletiva para a necessidade do desenvolvimento e da aplicação dessas tecnologias em prol do meio ambiente (CORRÊA et al., 2005).

Em um tipo de formação em que as técnicas microbianas de tratamento não são abordados, pode-se passar despercebido pela comunidade acadêmica a complexidade relativa a biodegradação dos resíduos gerados, bem como seu real impacto no ambiente. A partir daí, a pertinência da relação deste estudo com a educação ambiental, pautando-se em um senso crítico, reflexivo, sob um enfoque holístico, de que tudo está interligado (BERNA, 2001) e que as ações de organismos microscópicos podem influenciar diretamente a vida no planeta, uma vez que são os principais responsáveis pela ciclagem de nutrientes nos ecossistemas (MOREIRA; SIQUEIRA apud BERNA, 2001).

\section{Biodegradação de poluentes e biorremediação de áreas impactadas por micro-organismos}

Os estudos de degradação de compostos químicos têm mostrado vários micro-organismos extremamente versáteis em catabolizar moléculas recalcitrantes. Trabalhos atuais em biotecnologia indicam fungos e bactérias como principais micro-organismos eficientes na degradação de poluentes, possuindo alto potencial de ação na recuperação de ambientes contaminados (BALAN, 2002).

Vários organismos podem ser utilizados na degradação, como bactérias, fungos ou plantas (biodegradação), e a eficiência de um ou outro depende, em muitos casos, da estrutura da molécula e da presença de enzimas hábeis em degradar o produto, as quais apresentam especificidade para a maioria dos substratos (MEYER, 1978). É por meio deste mecanismo que a biorremediação é efetivada. Este processo é mais provável quando a estrutura química do xenobiótico é semelhante à estrutura de moléculas naturais (GAYLARD; BELLINASO; MANFIO, 2005).

Biorremediação é um processo no qual organismos vivos, normalmente plantas, microorganismos ou suas enzimas, são utilizados tecnologicamente para remover (remediar) ou reduzir poluentes no ambiente. $O$ processo metabólico que tem se mostrado mais apto em biodegradar moléculas xenobióticas (moléculas estranhas ao ambiente natural) recalcitrantes (moléculas de difícil degradação) nos processos de biorremediação, é o microbiano, uma vez que os microorganismos desempenham a tarefa de reciclar a maior parte das moléculas da biosfera, 


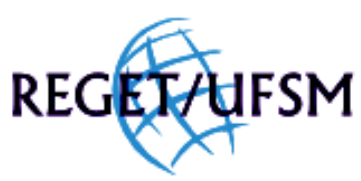

Pereira \& Freitas, v(6), no 6, p. $975-1006,2012$.

participando dos principais ciclos biogeoquímicos e representando, portanto, o suporte de manutenção da vida na Terra (GAYLARD; BELLINASO; MANFIO, 2005).

Segundo Yakubu (2007), o termo biorremediação pode ser definido como um processo biotecnológico no qual se utiliza o metabolismo de micro-organismos para a eliminação rápida de poluentes, com o objetivo de reduzir sua concentração a níveis aceitáveis, transformado-os em compostos de baixa toxicidade.

A Agência de Proteção Ambiental Americana (US-EPA) define biorremediação como "o processo de tratamento que utiliza a ocorrência natural de micro-organismos para degradar substâncias toxicamente perigosas, transformando-as em substâncias inócuas". Outro órgão, o American Heritage Dictionary of the American Language, adota a seguinte definição: o uso de agentes biológicos como bactérias e plantas, para remover ou neutralizar contaminantes do solo e da água (MARTINS et al., 2005).

A estrutura química dos poluentes orgânicos influência a metabolização destes por microorganismos, especialmente com respeito às taxas e à extensão da biodegradação. Alguns compostos orgânicos são rapidamente biodegradados enquanto outros são recalcitrantes (não biodegradáveis) (ATLAS, 1981). Se as enzimas que catabolizam a degradação de compostos naturais apresentam baixa especificidade pelo seu substrato, os xenobióticos com estrutura química semelhante a estes compostos naturais podem ser reconhecidos pelo sistema ativo da enzima e, assim, aproveitados pelo micro-organismo como fonte de nutrientes e energia (GAYLARD; BELLINASO; MANFIO, 2005).

Assim, a degradação do poluente é baseada em processos nos quais ocorrem reações bioquímicas mediadas por micro-organismos. Em geral, um composto orgânico, quando é oxidado, perde elétrons para um aceptor final de elétrons, que é reduzido (ganha elétrons). 0 oxigênio atua comumente como aceptor final de elétrons, sendo que a oxidação de compostos orgânicos com a redução do oxigênio molecular é chamada de respiração aeróbia heterotrófica. No entanto, quando o oxigênio não está presente, os micro-organismos podem usar compostos orgânicos ou íons inorgânicos como aceptores finais de elétrons, condições estas chamadas de anaeróbias. A biodegradação anaeróbia pode ocorrer por desnitrificação, redução do ferro, redução do sulfato ou condições metanogênicas (CORDAZZO, 2000).

Segundo Grady (1985), a comunidade microbiana envolvida na degradação de compostos xenobióticos atua em um processo denominado cometabolismo. Neste, os micro-organismos são divididos em primários e secundários. Os primários são aqueles capazes de metabolizar o substrato principal fornecido ao sistema, enquanto os secundários não utilizam o substrato principal, porém, os produtos liberados pelos micro-organismos primários.

\section{Principais micro-organismos utilizados em biorremediação}

Nas últimas décadas, a utilização de fungos filamentosos e seus metabólitos nos processos de biorremediação vem crescendo, em virtude do alto potencial degradativo, biossortivo (metais e corantes) e dos mecanismos de resistência em condições ambientais adversas (CONCEIÇÃO et al., 2005).

Os fungos apresentam uma série de características que os tornam interessantes para aplicação em sistemas de biorremediação. São elas: capacidade de crescer sob as condições de 


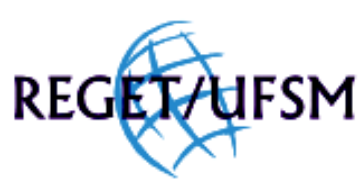

Pereira \& Freitas, v(6), no 6, p. $975-1006,2012$.

estresse ambiental que podem limitar o crescimento bacteriano; seu modo de crescimento, induzido quimiostaticamente em direção à fonte de carbono orgânico, por meio do alongamento e ramificação das hifas, que permitem a colonização de grandes áreas e o sistema de biodegradação fúngico, realizado por enzimas extracelulares. Dessa forma, o contato superficial com o contaminante é otimizado, aumentando sua biodisponibilidade e, consequentemente, sua biodegradação (CHANDER; ARORA; BATH, 2004).

Os fungos da podridão branca são degradadores naturais de lignina, celulose e hemicelulose. Tanto moléculas de lignina como alguns poluentes contêm compostos fenólicos, diésteres e bifenilas e, assim, o sistema enzimático destes organismos tem sido estudado na degradação de outras moléculas recalcitrantes (BALAN; MONTEIRO, 2001).

Muitos fungos e bactérias têm sido utilizados na remoção de metais pesados de efluentes industriais e do ambiente. Sabe-se que um grande número de compostos ligantes de metais é produzido por estes micro-organismos, tais como os ácidos orgânicos simples, alcoóis e macromoléculas, polissacarídeos, ácidos húmico e fúlvico (SAYER; GADD, 2001), alguns polissacarídeos, mucopolissacarídeos e proteínas (ZINKEVICH et al., 1996).

Além disso, esses micro-organismos podem adsorver estes metais a componentes presentes na superfície da parede celular (processo denominado biossorção), bioacumulá-los em organelas ou ligá-los a proteínas de seu interior celular (MELO; AZEVEDO, 2008). O uso de fungos filamentosos tem se destacado em relação aos outros micro-organismos na remoção de metais do ambiente, pois eles apresentam maior resistência a metais tóxicos, o que proporciona seu crescimento e desenvolvimento em meios que contenham altas concentrações desses poluentes (COLLINS; STOTZKY, 1992).

Segundo Gadd e White (1989), uma levedura muito utilizada para a remoção de metais tóxicos do ambiente é a levedura Saccaromyces cereviseae. Provavelmente, o mecanismo de remoção desses elementos por este fungo se da por meio do processo de bioacumulação.

De acordo com Kurek, Czoban e Bollag (1982), a biomassa dos fungos dos gêneros Penicillium, Aspergillus, Rhizopus, Mucor, Saccaromyces e Trichoderma têm se mostrado muito eficientes na remoção de metais pesados de soluções aquosas.

Muitos micro-organismos também têm sido utilizados para a degradação de gasolina, óleo diesel e resíduos de petróleo provenientes de derramamentos, nos oceanos ou no solo. Dentre os hidrocarbonetos que compõem estes resíduos, os mais tóxicos e que causam maior preocupação são os chamados BTEX (benzeno, tolueno, etilbenzeno e os três isômeros de posição do xileno). Estes compostos são utilizados como fonte de carbono por diversas espécies de bactérias, leveduras e fungos filamentosos (TEIXEIRA, 2007).

Teixeira (2007), obteve bons resultados na degradação de gasolina comercial por bactérias das espécies Pseudomonas putida e Pseudomonas aeruginosa. Outros gêneros de bactérias têm sido descritos como potenciais degradadoras de petróleo de ambientes comtaminados, como Acidovorans, Acinetobacter, Agrobacterium, Alcaligenes, Aeromonas, Arthrobacter, Beijemickia, Burkholderia, Bacillus, Comomonas, Corynebacterium, Cycloclasticus, Flavobacterium, Gordonia, Microbacterium, Moraxella, Mycobacterium, Micrococcus, Neptunomonas, Nocardia, Paracoccus, Pasteurella, Polaromonas, Pseudomonas, Ralstonia, Rhodococcus, Sphingomonas, Stenotrophomonas, Streptomyces e Vibrio (CRAPEZ et al., 2002; JACQUES et al., 2007; MANDRI; LIN, 2007, SEO et al. apud TONINI; REZENDE; GRATIVO, 2010).

Outro tipo de poluente que tem despertado grande preocupação nos ambientalistas são os pesticidas. $\mathrm{O}$ uso de agrotóxicos tem se difundido muito na agricultura, nos últimos trinta anos, especialmente no Brasil, que se tornou um dos maiores consumidores desses xenobióticos, ficando atrás somente do Japão e dos Estados Unidos (DAMS, 2006). Felizmente, muitos micro- 
ReG(F)

Pereira \& Freitas, v(6), no 6, p. $975-1006,2012$.

1001

Rev. Elet. em Gestão, Educação e Tecnologia Ambiental

(e-ISSN: 2236-1170)

organismos têm sido utilizados na degradação destes compostos em solos ou em efluentes. Dentre eles, diversas bactérias, como espécies de Nocardia, Pseudomonas e agrobactérias (YANZEKONTCHOU; GSCHWIND, 1994); e, dentre os fungos filamentosos, Aspergillus fumigatus e Rhizopus stolonifer (BEHKI et al., 1993).

\section{Estratégias utilizadas em biorremediação}

Segundo Bento, Camargo e Okeke (2003), as estratégias de biorremediação incluem a utilização de micro-organismos autóctones, ou seja, do próprio local, sem qualquer interferência de tecnologias ativas de remediação (biorremediação intrínseca ou natural); a adição de agentes estimulantes, como nutrientes, oxigênio e biossurfactantes (bioestimulação) e a inoculação de consórcios microbianos enriquecidos (bioaumento).

\section{Biorremediação in situ}

A biorremediação in situ é realizada no próprio local, sem que haja remoção de material contaminado. Isto evita custos e distúrbios ambientais associados com o movimento de solos e águas de um local contaminado para outros locais destinados ao tratamento. Os produtos finais de uma biorremediação efetiva, são água e gás carbônico (processo denominado mineralização), compostos estes, que não apresentam toxicidade e que podem ser incorporados ao ambiente sem prejuízo aos organismos vivos (MARIANO, 2006).

$\mathrm{Na}$ mineralização, o substrato absorvido é quebrado em moléculas menores que, posteriormente serão metabolizadas por reações que geram energia. Consequentemente, a biomassa da população aumenta às custas do substrato e a concentração deste diminui consideravelmente com a expansão da população microbiana. Neste processo, a molécula é degradada completamente a moléculas inorgânicas de ocorrência universal, como $\mathrm{CO}_{2}, \mathrm{CO}, \mathrm{H}_{2} \mathrm{O}$, $\mathrm{NH}_{3}, \mathrm{H}_{2} \mathrm{~S}$ e HCL. É portanto, o único meio de eliminar um composto xenobiótico do ambiente (MELO; AZEVEDO, 2008).

Uma das técnicas in situ é a biorremediação passiva ou intrínseca, também denominada atenuação natural, na qual o contaminante permanece no local e, por meio de processos naturais, como biodegradação, volatilização (quebra da molécula em compostos voláteis), diluição (diminuição da concentração inicial do poluente) e sorção (adsorção do poluentes a parede celular microbiana ou a seus metabólitos), ocorre a descontaminação do ambiente (MULLIGAN; YONG, 2004). Por depender exclusivamente destes processos naturais, a biorremediação passiva pode ser muito lenta, exigindo o uso conjunto de outras técnicas e, obrigatoriamente, o monitoramento do local por longos períodos de tempo, visando à proteção da saúde do homem e do ambiente (JACQUES et al., 2007).

Quando a baixa taxa de degradação de um contaminante no solo é resultado do número reduzido ou inexistente de micro-organismos com habilidade de degradação do composto, a bioaumentação ou a bioestimulação são técnicas recomendadas. A bioaumentação é uma técnica de biorremediação in situ que consiste na inoculação de microrganismos com alto potencial de degradação dos contaminantes no local contaminado (EDGEHILL, 1999). A bioestimulação é a 


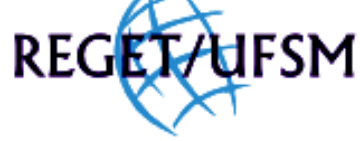

Rev. Elet. em Gestão, Educação e Tecnologia Ambiental

(e-ISSN: 2236-1170)

introdução de nutrientes orgânicos e inorgânicos no solo, visando estimular a atividade dos microorganismos nativos em degradar o composto poluente (JACQUES et al., 2007).

\section{Biorremediação ex situ}

Quando há a necessidade de retirada de solo ou efluente do local contaminado para que os mesmos sejam tratados em outro local, o processo é chamado de biorremediação ex situ. A remoção pode ser necessária quando há possibilidade contaminação de pessoas e do ambiente próximo do solo a ser biorremediado, ou quando a presença de altas concentrações de contaminantes demanda a utilização de técnicas como compostagem, biorreatores, entre outras (JACQUES et al., 2007).

A compostagem é uma técnica ex situ em que o solo contaminado é removido do local de origem e alocado na forma de pilhas, em um local que permita o controle da lixiviação e do escoamento superficial dos líquidos originados dessas pilhas. Neste solo, será desencadeado um processo em que os micro-organismos aeróbios irão degradar os contaminantes orgânicos, transformando-os em material orgânico estabilizado, $\mathrm{CO}_{2}$ e água (AHTIAINEN et al., 2002). Este último é utilizado no tratamento da parte orgânica do resíduo sólido urbano.

A utilização de aterros sanitários, é um outro método de tratamento de rejeitos sólidos muito utilizado nos grandes centros urbanos. Neste, o processo de decomposição é anaeróbio em razão da escassez de ar dentro das células; já no processo de compostagem, ocorre uma digestão aeróbia do resíduo orgânico. O composto produzido, geralmente, contém uma quantidade total de nitrogênio, fósforo e potássio entre $1,5 \%$ a $2,5 \%$ do peso, enquanto um adubo deve ter, no mínimo, 24\%. Assim, o composto orgânico é considerado condicionador do solo (PHILIPPI JÚNIOR; ROMERO; BRUNA, 2004).

Outro processo de tratamento muito utilizado no processo de remediação ex situ é o emprego de reatores biológicos. Os processos biológicos dividem-se em aeróbios e anaeróbios. Dentre os reatores utilizados, os mais comuns são os filtros biológicos anaeróbios ou aeróbios, o sistema de lodos ativados e suas variações e os digestores anaeróbios de fluxo ascendente (PHILIPPI JÚNIOR; ROMERO; BRUNA, 2004).

Existe uma infinidade de tipos e configurações de biorreatores que podem ser comparados a tanques aéreos fechados. O solo ou o efluente são acondicionados em tanques mecanicamente agitados, o que possibilita o aumento da disponibilidade dos contaminantes aos micro-organismos degradadores e a eliminação da heterogeneidade da distribuição dos contaminantes. Além disso, no interior do biorreator, as condições ambientais de pH, os nutrientes, a aeração (ou anaerobiose) e a temperatura são otimizados para o máximo crescimento microbiano, sendo possível também, a inoculação de micro-organismos com capacidade degradativa conhecida, o que torna o processo bastante eficiente (MACLEOD; DAUGULIS, 2005). O fator que normalmente limita a utilização desta técnica é o elevado custo do tratamento, devido principalmente, à alta tecnologia utilizada nos biorreatores (DOELMAN; BREEDVELK, 1999).

Nos filtros biológicos aeróbicos, que são tanques normalmente preenchidos por pedras ou plásticos utilizados como suporte para o crescimento microbiano, ocorre o desenvolvimento de uma fina camada de micro-organismos aeróbicos, denominada biofilme. A água residuária quando percola pelo filtro e entra em contato com o filme biológico, tem sua matéria orgânica adsorvida pela massa biológica, na qual é estabilizada pelos micro-organismos anaeróbicos (PHILIPPI JÚNIOR; ROMERO; BRUNA, 2004). 


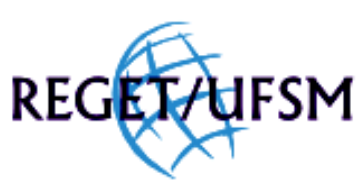

Pereira \& Freitas, v(6), no 6, p. $975-1006,2012$.

Dentre os processos biológicos aeróbios, o sistema de lodos ativados é o mais utilizado no tratamento de águas residuárias, sendo a alternativa aplicada em mais de $90 \%$ das ETEs de médio e grande porte dos países desenvolvidos (MENDONÇA, 2002).

O sistema de lodos ativados consiste em provocar o desenvolvimento de uma cultura microbiológica na forma de flocos (lodos ativados) em um tanque com aeração mecânica, durante o tempo necessário para a metabolização da matéria orgânica presente no efluente a ser tratado, vindo a constituir uma mistura denominada licor. Este licor é enviado continuamente a um decantador (decantador secundário), destinado a separar o efluente tratado do lodo. O lodo é recirculado ao tanque de aeração a fim de manter a concentração de microrganismos ideal ao tratamento. O sobrenadante do decantador é o efluente tratado, pronto para ser descartado no corpo receptor. $\mathrm{O}$ excesso de lodo decorrente do crescimento biológico, é extraído do sistema sempre que a concentração do licor ultrapassa os valores de projeto. Este lodo pode então ser desidratado, tendo como possível aplicação a adubação de culturas agrícolas (JENKINS; RICHARD; DAIGGER, 2003).

A capacidade de depuração do sistema de lodos ativados se deve às atividades metabólicas dos micro-organismos presentes, não só de bactérias, mas também de protozoários (flagelados, ciliados e amebas), micrometazoários (rotíferos, nematoides e tardígrados), algas (filamentosas e não-filamentosas), fungos, dentre outros. Esta diversidade confere relevante importância ao acompanhamento da microbiologia dos lodos ativados para o entendimento e o controle do processo de tratamento (CETESB).

Um sistema que vem ganhando espaço por apresentar várias vantagens é o de tratamento anaeróbio, mais especificamente, o tratamento anaeróbio de fluxo ascendente com manta de lodo, conhecido como reator UASB (SILVEIRA et al. 2007).

Estes reatores possuem também retenção de biomassa microbiana no compartimento de reação, onde se desenvolve uma manta de lodo, que é atravessada pelo efluente, e uma recirculação de parte da biomassa, que é carreada pela fase líquida efluente desse compartimento. Esta recirculação é alcançada por meio de sua sedimentação no compartimento de decantação, seguida de retorno, por simples gravidade, para o compartimento de reação (VON SPERLING; FREIRE; CHERNICHARO, 2000).

$O$ tratamento de efluentes utilizando reator UASB constitui um método eficiente e de custo relativamente baixo, para a remoção de matéria orgânica e de sólidos em suspensão, diminuindo consideravelmente o potencial poluidor dos efluentes após o tratamento. As grandes vantagens de um UASB são a sua eficiência de remoção de matéria orgânica ( alta demanda bioquímica de oxigênio - $\mathrm{DBO}$ ) e de sólidos, além de um curto tempo de tratamento: 6 horas para a remoção de $80 \%$ de DBO e $75 \%$ dos sólidos em suspensão. Em sistemas de lodo ativado e em lagoas de estabilização, o tempo de permanência é da ordem de 12 a 24 horas e de 20 a 30 dias, respectivamente (BEZERRA, 1998). Entretanto, esse tipo de reator também apresenta algumas desvantagens, como sua baixa eficiência quanto à remoção de patógenos e nutrientes. Assim, a fim de otimizar esse tipo de tratamento, utiliza-se uma combinação deste com lagoas de estabilização, podendo-se, assim, obter um efluente de boa qualidade higiênica em um sistema que ocupa menos que a metade da área necessária para um sistema de lagoas convencionais (DIXON et al., 1995).

A combinação do UASB com um sistema de lodos ativados também é uma alternativa, pois permite obter uma melhor qualidade do efluente final, com menos da metade do volume de reatores, da produção de lodo e do consumo de oxigênio de um sistema convencional de lodos ativados. Dessa maneira, a utilização de reatores do tipo UASB deve ser precedida de um tratamento em lagoas de estabilização ou de lodos ativados, para que o processo seja otimizado 
A utilização de micro-organismos nativos ou introduzidos no ambiente, em reatores biológicos, é realizada com sucesso em refinarias de petróleo, indústrias têxteis, de celulose e farmacêutica, dentre outras. Entretanto, nem sempre os indivíduos fundamentais para os processos de biorremediação estão presentes, ou encontram-se em número reduzido. A solução para este problema é procurar no ambiente aqueles que possuam os dispositivos metabólicos apropriados para mineralizar (degradar totalmente), iniciar a degradação ou diminuir o efeito tóxico de determinados compostos (SPAIN; PRITCHARD; BOURQUIN, 1980) e inseri-los nestes biorreatores.

Lagoas de estabilização aeradas, facultativas ou anaeróbias, também são alternativas de tratamento ex situ de poluentes (PHILIPPI JÚNIOR; ROMERO; BRUNA, 2004). As lagoas de estabilização são grandes tanques escavados no solo, nos quais as águas residuárias são tratadas por processos naturais controlados unicamente pela vazão dos efluentes, além da eventual dosagem de produtos químicos para ajuste de $\mathrm{pH}$ ou de nutrientes. As lagoas anaeróbias são dimensionadas para receber elevadas cargas orgânicas e funcionam sem oxigênio dissolvido. As facultativas possuem uma camada superior, com o desenvolvimento de algas e microrganismos aeróbios que se encontram numa simbiose. Enquanto as algas realizam a fotossíntese, consumindo o gás carbônico e liberando o oxigênio, os micro-organismos oxidam a matéria orgânica, utilizando o oxigênio e liberando o gás carbônico. Na camada do fundo, o processo se comporta como na lagoa anaeróbica. As aeróbicas são semelhante às facultativas, entretanto, são bem rasas, e assim, não há depreciação de oxigênio no fundo da lagoa, e, consequentemente, de micro-organismos anaeróbios (PHILIPPI JÚNIOR; ROMERO; BRUNA, 2004).

\section{CONSIDERAÇÕES FINAIS}

A partir da leitura desta revisão é possível compreender a importância do uso dos microorganismos como ferramenta biotecnológica para a remediação de áreas contaminadas, bem como para o tratamento dos mais diversos tipos de resíduos.

Pode-se observar, por meio da leitura deste projeto, a importância dos organismos nativos do ambiente, como fungos, bactérias e leveduras, em ciclar toda e qualquer matéria orgânica natural ou xenobiótica que é disposta no ambiente devido a ações antropogênicas.

Dessa forma, as citações aqui listadas auxiliam os docentes no ensino da educação ambiental não somente por meio das vertentes tradicionalmente abordadas, mas sim, através de uma visão holística e interdisciplinar do processo, em que os atores responsáveis pelo desaparecimento desses poluentes são estudados a fundo e com a sua devida importância.

\section{REFERÊNCIAS}

AHTIAINEN, J. et al. Microbial toxicity tests and chemical analysis as monitoring parameters at composting of creosotecontaminated soil. Ecotoxicology and Environmental Safety, San Diego, v. 53, n. 3, p. 323-329, June 2002.

ATLAS, R. M. Microbial degradation of petroleum hydrocarbons: an environmental perspective. Microbiological Reviews, Bethesda, v. 45, n. 1, p. 180-208, Mar. 1981.

BALAN, D. S. L. A indústria têxtil e o meio ambiente. Tecnologia limpa e controle ambiental. Química Têxtil, Barueri, v. 66, p. 26-31, 2002. 
BALAN, D. S. L.; MONTEIRO, R. T. R. Decolorization of textile índigo dye by ligninolytic fungi. Journal of Biotechnology, Amsterdam, v. 89, n. 2-3, p. 141-145, Aug. 2001.

BEHKI, R. M. et al. Degradation of atrazine, propazine, and simazine by Rhodococcus strain B-30. Journal of Agricultural and Food Chemistry, Easton, v. 42, n. 5, p. 1237-1241, May 1993.

BENTO, F. M.; CAMARGO, F. A. O.; OKEKE, B. Bioremediation of soil contaminated by diesel oil. Brazilian Journal of Microbiology, São Paulo, v.34, supl.1, p. 65-68, Nov. 2003.

BERNA, V. Como fazer educação ambiental. São Paulo: Paulus, 2001.

BEZERRA, S. M. C. Influência do tempo de detenção hidráulica sobre a auto-inoculação na partida de um reator UASB tratando Esgoto Sanitário. 143 f. 1998. Dissertação (Mestrado) - Universidade Federal da Paraíba, Campina Grande.

BRITO, N. N. et al. Utilização de fungos na remediação de efluentes industriais. In: FÓRUM DE ESTUDOS CONTÁBEIS, 4., 2004, Rio Claro. Anais... Rio Claro: Faculdades Integradas Claretianas, 2004.

BUNCE, N. J. Environmental chemistry. Canadá: Wuerz, 1994.

CATUNDA, P. F.; VAN HAANDEL, A. C. Activated sludge settlers: design and optimization. Water Science and Technology, Oxford, v. 19, n. 3-4, p. 613-623, 1980.

CHANDER, M.; ARORA, D. S.; BATH, H. K. Biodecolourisation of some industrial dyes by white-rot fungi. Journal of Industrial Microbiology and Biotechnology, Hampshire, v. 31, n. 2, p. 94-97, 2004.

COLLINS, Y. E.; STOTZKY, G. Heavy metal alter the electrokinetic properties of bacteria, yeast and clay minerals. Applied and Environmental Microbiology, New York, v. 58, n. 5, p. 1592-1600, May 1992.

COMPANHIA DE TECNOLOGIA DE SANEAMENTO AMBIENTAL. Compilação de técnicas de prevenção à população para a indústria têxtil. São Paulo: CETESB, 2009. Disponível em: <http:\|www.cetesb. sp.gov.br>. Acesso em: 07 jul. 2011.

CONCEIÇÃO, D. M. et al. Fungos filamentosos isolados do rio Atibais, SP e refinaria de petróleo biodegradadores de compostos fenólicos. Arquivos do Instituto Biológico, São Paulo, v. 72, n. 1, p. 99-106, jan./mar. 2005.

CORDAZZO, J. Modelagem e simulação numérica do derramamento de gasolina acrescida de álcool em águas subterrâneas. 120 f. 2000. Dissertação (Mestrado) - Departamento de Engenharia Mecânica, Universidade Federal de Santa Catarina, Florianópolis.

CORRÊA, L. B. et al. O saber resíduos sólidos de serviços de saúde na formação acadêmica: uma contribuição da educação ambiental. Interface: comunicação, saúde, educação, Rio Grande do Sul, v. 9, n. 18, p. 571-84, set./dez. 2005.

DAMS, R. I. Pesticida: usos e perigos à saúde e ao meio ambiente. Revista Saúde e Ambiente, Joinville, v. 7, n. 2, p. 37 44, dez. 2006.

DEL PINO, J. C.; KRÜGER, V.; SCHROEDER, E. O. Relações entre química e educação. Utopia e Ação: revista da próreitoria de extensão, Rio Grande do Sul, v. 2, p. 141-153, 1995.

DELLAMATRICE, P. M. Biodegradação e toxicidade de corantes têxteis e efluentes da Estação de Tratamento de Águas Residuárias de Americana. 137 f. 2005. Tese (Doutorado em Ecologia de Agroecossistemas) - Escola Superior de Agricultura Luiz de Queiroz, Universidade de São Paulo, Piracicaba.

DIXON, N. G. H. et al. Removal of pathogenic organisms from the effluent of na upflow anaerobic digester using waste stabilization ponds. Water Science and Technology, Oxford, v. 31, n. 12, p. 275-284, 1995.

DOELMAN, P.; BREEDVELK, G. In situ versus on site practices. In: ADRIANO, D. C. et al. (Ed.). Bioremediation of contaminated soils. Madison: ASA, 1999. p. 539-558.

FREIRE, R. S. et al. Novas tendências para o tratamento de resíduos industriais contendo espécies organocloradas. Química Nova, São Paulo, v. 23, n. 4, p. 504-511, 2000.

GADD, G. M.; WHITE, C. Heavy metal and radionuclide accumulation and toxicity in fungi and yeast. In: POLE, R. K.; GADD, G. M. (Ed.). Metal microbe interactions. Oxford: IRL, 1989. p. 19-38.

GAYLARD, C. C.; BELLINASO, M. L.; MANFIO, G. P. Aspectos biológicos e técnicas da biorremediação de xenobióticos. Biotecnologia, Ciência e Desenvolvimento, Brasília, v. 8, n. 34, jan./jun. 2005. Disponível em: <http://www.biotecnologia.com.br/edicoes/ed34.php>. Acesso em: 10 set. 2011.

GRADY, C. P. L. Biodegradation: its measurement and microbiological basis. Biotechnology \& Bioengineering, New York, v. 27, n. 5, p. 660-674, May 1985.

GUNTHER, W. M. R. Poluição dos solos. In: PHILIPPI JÚNIOR, A.; PELICIONI, M. C. (Org.). Educação ambiental e sustentabilidade. São Paulo: Manole, 2005. p. 195-215.

JACOBI, P. Educação ambiental, cidadania e sustentabilidade. Cadernos de Pesquisa, São Paulo, n. 118, p. 185-205, mar. 2003.

JACQUES, R. J. S. et al. Biorremediação de solos contaminados com hidrocarbonetos aromáticos policíclicos. Ciência Rural, Santa Maria, v. 37, n. 4, p. 1192-1201, 2007. 
JENKINS, D.; RICHARD, M. G.; DAIGGER, G. T. Manual oh the causes and control of activated sludge bulking, foaming, and other solids separation problems. 3. ed. London: Lewis Publishers, 2003.

KUNZ, A.; ZAMORA, P. P. Novas tendências no tratamento de efluentes têxteis. Quimica Nova, São Paulo, v. 25, n. 1, p. 78-82, 2002.

KUREK, E.; CZOBAN, J.; BOLLAG, J. Sorption of cadmium by microorganisms in competition with other soil constitutes. Applied and Environmental Microbiology, Washington, v. 43, n. 5, p. 1011-1015, May 1982.

MARIANO, A. P. Avaliação do potencial de biorremediação de solos e de águas subterrâneas contaminados com óleo diesel. 147 f. 2006. Tese (Doutorado em Geociências e Meio Ambiente) - Programa de Pós-Graduação em Geociências e Meio Ambiente, Universidade Estadual Paulista, Rio Claro, 2006.

MELO, I. S.; AZEVEDO, J. L. Microbiologia ambiental. 2. ed. rev. e ampl. Jaguariúna: Embrapa Meio Ambiente, 2008. MENDONÇA, L. C. Microbiologia e cinética do sistema de lodos ativados como pós-tratamento de efluente de reator anaeróbio de leito expandido. 217 f. 2002. Tese (Doutorado) - Escola de Engenharia de São Carlos, Universidade de São Paulo, São Paulo.

MEYER, U. Biodegradation of synthetic organic colorants. In: BROWN, A. W. A. Ecology of pesticides. New York: Jhon Willey, 1978.

MULLIGAN, C. N.; YONG, R. N. Natural attenuation of contaminated soil. Environmental International, Oxford, v.30, n. 4, p. 587-601, Apr. 2004.

PHILIPPI JÚNIOR, A.; ROMERO, M. A.; BRUNA, G. C. (Ed.). Curso de gestão ambiental. Brueri,: Manole, 2004.

RODRIGUES, S.; DUARTE, A. C. Poluição do solo: revisão generalista dos principais problemas. In: CASTRO, A.; DUARTE, A.; SANTOS, T. (Ed.). O ambiente e a saúde. Lisboa: Instituto Piaget, 2003. p. 136-176.

SAYER, J. A.; GADD, G. M. Binding of cobalt and zinc by organic acids and culture filtrates of Aspergillus niger grown in the absence or presence of insoluble cobalt or zinc phosphate. Mycological Research, Cambridge, v. 105, p.12611267, Nov. 2001.

SECRETARIA DO MEIO AMBIENTE DO ESTAdO DE SAO PAULO. São Paulo: Secretaria do Meio Ambiente, 2011. Disponível em: <http://www.ambiente.sp.gov.br/>. Acesso em: 15 set. 2011.

SILVEIRA, B. I. et al. Avaliação do desempenho de um reator UASB de uma planta industrial de tratamento de efluentes líquidos. In: 1INTERNATIONAL WORKSHOP ADVANCES IN CLEANER PRODUCTION, 1., 2007, São Paulo. Anais... São Paulo: UNIP. 2007. Disponível em: <www.advancesincleanerproduction.net>. Acesso em: 20 set. 2011.

SPAIN, J. C.; PRITCHARD, P. H.; BOURQUIN, A. W. Effects of adaptation on biodegradation rates in sediment/water cores from estuarine and freschwater environments. Applied and Environmental Microbiology, Washington, v. 40, n. 4, p.726-734, Apr. 1980.

TEIXEIRA, A. S. Isolamento e caracterização de bactérias degradadoras de gazolina commercial. 95 f. 2007. Dissertação (Mestrado em Ciência do Solo) - Faculdade de Agronomia, Universidade Federal do Rio grande do Sul, Porto Alegre.

TONINI, R. M. C. W.; REZENDE, C. E. de; GRATIVO, A. D. Degradação e biorremediação de compostos do petróleo por bactérias: revisão. Oecologia Australis, Rio de Janeiro, v. 14, n. 4, p. 1010-1020, dez. 2010.

VON SPERLING, M.; FREIRE, V. H.; CHERNICHARO, C. A. L. Performance evaluation of an UASB: activated sludge system treating municipal wastewater. In: WORLD WATER CONGRESS OF THE INTERNATIONAL WATER ASSOCIATION, 1. 2000, Paris. Anais... Paris: IWA, 2000. p. 94-100.

YAKUBU, M. B. Biological approach to oil spills remediation in the soil. African Journal of Biotechnology, Nigeria, v. 6, n. 24, p. 2735-2739, Dec. 2007.

YANZE-KONTCHOU, C.; GSCHWIND, N. Mineralization of the herbicide atrazine as a carbon source by a Pseudomonas strain.; Appl. Environmental Microbiology, Oxford, v. 60, n. 12, p. 4297-4302, Dec. 1994.

ZINKEVICH, V. et al. Characterization of exopolymers produced by different isolates of marine sulphate-reducing bacteria. International Biodeterioration Biodegradation, Barking, v. 37, n. 3-4, p. 163-172, 1996. 